\title{
NAS TEIAS DA ADMINISTRAÇÃO COLONIAL: OS GOVERNADORES DA CAPITANIA DE GOIÁS (1749-1822)
}

\author{
IN THE TEA OF COLONIAL ADMINISTRATION: THE GOVERNORS OF THE \\ CAPITANIA DE GOIÁS (1749-1822)
}

\author{
Alan Ricardo Duarte Pereira* \\ Cristina de Cássia Pereira Moraes**
}

\begin{abstract}
RESUMO
O interesse pelo estudo dos governadores ganhou destaque nos últimos anos. Embora tenha sido um tema citado em muitos trabalhos sobre o dito "Brasil Colonial" produzidos entre a década de 1970 e 1980, pouco se aprofundou ou discutiu a figura dos governadores, especialmente no que se refere às suas funções, origens sociais, trajetórias no ultramar, alianças e vinculos politicos. Nesse contexto, a historiografia sobre os governadores na Capitania de Goiás foi alvo de atenção de alguns estudiosos. Busca-se, aqui, analisar tais trabalhos e compreender a historiografia sobre os governadores numa região ultramarina.
\end{abstract}

PALAVRAS-CHAVE: Capitania de Goiás. Governadores. Historiografia.

\begin{abstract}
Interest in the study of governors has gained prominence in recent years. Although it was a theme cited in many works on the so-called "Colonial Brazil" produced between the 1970s and 1980s, little has been deepened or discussed the figure of the governors, especially with regard to their functions, social origins, trajectories overseas, political alliances and ties. In this context, the historiography about the governors in the Captaincy of Goias has received the attention of some scholars. Here, we seek to analyze such works and understand historiography about governors in an overseas region.
\end{abstract}

KEY WORDS: Captaincy of Goiás. Governors. Historiography.

As capitanias na América portuguesa foram estruturadas de tal maneira que o cargo de governador era o mais reputado. Ora, se fosse possível desenhar uma hierarquia entre os cargos ultramarinos, provavelmente a figura do governador aparecia em primeiro lugar. Acontece, porém, que por trás dessa representação pulsa um segundo elemento: os governadores não agiam sozinhos e tampouco administravam uma vasta capitania isoladamente. Tinham ao seu lado uma variedade de

\footnotetext{
* Professor da Rede Municipal de Goiânia. Doutor em História pela Universidade Federal de Goiás (UFG). E-mail: alanricardoduarte@gmail.com.

** Professora Associada da Universidade Federal de Goiás (UFG). Doutorado em História das Ideias pela Universidade Nova de Lisboa. Pós-Doutorado pela Universidade de La Rochelle, França. E-mail: cristinadecassiapmoraes@gmail.com.
} 
indivíduos. Estudar os governadores é, ao mesmo tempo, lidar com esses personagens múltiplos que orbitavam ou mesmo (com)partilhavam das ações dos governadores.

O Quadro 1 nos mostra os governadores da Capitania de Goiás. Foram 10 governadores e capitães-generais durante a existência da Capitania de Goiás (1749-1822). Além disso, a capitania também recebeu juntas provisórias cujo objetivo era, entre outras coisas, administrar a região por um curto período. Eram escolhidos entre os moradores locais ${ }^{1}$ e atuaram, especialmente, na ausência ou afastamento dos governadores titulares. Numa carta de 1785, a Câmara de Vila Boa lembrava que a escolha do governador interino fosse determinada, sobretudo, pela antiguidade de patente. Por exemplo, no Quadro I vê-se o nome do governador João Manoel de Mello (1759-1770), que faleceu na capitania em 1770, vítima de uma apoplexia (ou, contemporaneamente, um derrame), e, naquela situação, foi convocada uma junta provisória para exercer a interinidade até a chegada de um novo governador.

Quadro 1 - Governadores e capitães-generais da Capitania de Goiás

\begin{tabular}{|c|c|}
\hline Nome & Posse \\
\hline Dom Marcos de Noronha, conde dos Arcos & 8 de Novembro de 1749 \\
\hline $\begin{array}{l}\text { Dom Álvaro José Xavier Botelho de Távora, conde de S. } \\
\text { Miguel }\end{array}$ & 31 de Agosto de 1755 \\
\hline João Manoel de Mello, capitã-general & 7 de Julho de 1759 \\
\hline $\begin{array}{l}\text { Antônio José Cabral d'Almeida, Antônio Thomaz da Costa } \\
\text { e Damião, José de Sá Pereira (Junta Provisória) }\end{array}$ & 13 de Abril de 1770 \\
\hline $\begin{array}{l}\text { Antônio Carlos X. Furtado de Mendonça, brigadeiro } \\
\text { (interino) }\end{array}$ & 15 de Agosto de 1770 \\
\hline $\begin{array}{l}\text { José de Almeida de Vasconcelos de Soveral e Carvalho, } \\
\text { barão de Mossâmedes }\end{array}$ & 26 de Julho de1772 \\
\hline $\begin{array}{l}\text { Antônio José Cabral de Almeida, João Pinto Barbosa } \\
\text { Pimentel e Pedro da Costa (Governo Provisório) }\end{array}$ & 17 de Maio de 1778 \\
\hline Luís da Cunha Menezes, capitão-general & -16 de Outubro de 1778 \\
\hline Tristão da Cunha Menezes, capitão-general & 22 de Junho de 1783 \\
\hline João Manoel de Menezes, capitão general & 25 de Fevereiro de 1800 \\
\hline Francisco de Assis Mascarenhas, capitão-general & 27 de Fevereiro de 1804 \\
\hline Fernando Delgado Freire de Castilho, capitão-general & 28 de Novembro de 1809 \\
\hline $\begin{array}{l}\text { Antônio José Álvares M. e Silva, Luís Antônio da Silva e } \\
\text { Souza e Álvaro José Xavier (Junta administrativa) }\end{array}$ & 2 de Agosto de 1820 \\
\hline Manoel Inácio de Sampaio e Pina, capitão-general & 4 de Outubro de 1820 \\
\hline $\begin{array}{l}\text { Manoel Inácio de Sampaio e Pina, capitão-general, Antônio } \\
\text { Pedro de Alencastro e Paulo Conceito d'Almeida Homem } \\
\text { (Junta Administrativa) }\end{array}$ & ----- \\
\hline $\begin{array}{l}\text { Francisco Xavier dos Guimarães Brito e Costa, Luís da } \\
\text { Costa Freire de Freitas, João José do Couto Guimarães e } \\
\text { Inácio Soares de Bulhões }\end{array}$ & 30 de Novembro de 1821 \\
\hline $\begin{array}{l}\text { Álvaro José Xavier, Joaquim Rodrigues Jardim, Raimundo } \\
\text { Nonato Hyacinto, João José do Couto Guimarães, Joaquim } \\
\text { Alves de Oliveira, Luís Gonzaga de Camargo Fleury (Junta } \\
\text { Provisória) }\end{array}$ & 8 de Abril de 1822 \\
\hline
\end{tabular}

Fonte: BRASIL. Catálogo de verbetes dos documentos manuscritos avulsos da Capitania de Goiás (1731-1822), existentes no Arquivo Histórico Ultramarino (AHU). Brasília: Ministério da Cultura, 2001.

O período de atuação dos governadores na Capitania de Goiás coincidiu, por sua vez, com acontecimentos ligados a Portugal. Pode-se elencar a própria organização do reinado português, com D.

\footnotetext{
${ }^{1}$ Em geral, foram escolhidos pelos membros da Câmara. Assim, tratava-se de indivíduos pertencentes aos quadros do oficialato régio com influência na capitania. Todos os governadores e vice-reis providos pela Coroa portuguesa saíram de Portugal. Foi prática comum nomear indivíduos "naturais de Portugal". A exceção, entretanto, se encontrava nos "governos interinos".
} 
José I (1750-1777), depois com D. Maria I (1777-1799), e a regência de seu filho, D. João (1799-1816). Os governadores da Capitania de Goiás foram escolhidos no contexto desses reinados, nomeadamente sob a dinastia de Bragança ${ }^{2}$ e seguiram as ações da Coroa portuguesa. Talvez uma das marcas fundamentais a se observar no setecentos foi, sobretudo, o chamado período pombalino, encabeçado pelo Secretário de Estado Sebastião José de Carvalho e Melo, o Marquês de Pombal. Em sua política para a América portuguesa, Pombal buscou expulsar os jesuítas, aldear os indígenas, criar e ampliar o oficialato militar, explorar o ouro, mediante a substituição da capitação pelo quinto. O exemplo maior de suas ações foi, sem dúvida, a publicação, em 1758, do Diretório, no qual expressava um "projeto" de colonização dos indígenas com aldeamentos, ensino da língua portuguesa, casamentos mistos e desenvolvimento econômico. No caso de Goiás, Dias (2017) explica que a aplicação do Diretório se iniciou com o governador José de Almeida de Vasconcelos de Soveral e Carvalho - futuro Barão de Mossâmedes - e que os governadores da família Cunha Menezes foram responsáveis por aplicar tais diretrizes.

Outra marca essencial desse contexto foi a escolha de nobres para o serviço ultramarino. Nesse sentido, os governadores da Capitania de Goiás pertenciam às principais casas nobres de Portugal. Por exemplo, dos dez governadores da Capitania de Goiás, oito eram oriundos da primeira nobreza de Portugal e dois eram fidalgos (MONTEIRO; CUNHA, 2005). Sob o reinado de D. José I e de outros reis portugueses, a Coroa portuguesa recrutou os governadores no âmago da nobreza e, além disso, conferiu títulos e privilégios a esses governadores (MONTEIRO, 2003). Em resumo, a nobreza não só se aliou aos reis portugueses da Dinastia de Bragança como ganhou da monarquia títulos e acrescentamentos simbólicos e materiais.

A jurisdição do governador era determinada pela Instrução e pelos Regimentos. Segundo Santos (2011), a Instrução trazia orientações específicas e pontuais para a capitania. Por sua vez, os Regimentos eram mais duradouros e contemplavam questões amplas. Tais documentos foram elaborados pela Coroa portuguesa, especialmente pelo Conselho Ultramarino, e acrescentado pelos governadores.

Desde 1548. com a implantação do governo-geral na América portuguesa, os indivíduos que ocupavam o cargo de governador recebiam um regimento no qual estavam detalhados sua jurisdição e campo de ação. Os primeiros regimentos foram entregues a Tomé de Sousa (1549-1553), Francisco Giraldes (1558), Gaspar de Sousa (1612-1617), Diogo de Mendonça Furtado (1621-1624) e Roque da Costa Barreto (1678-1682). Segundo Consentino (2005), esses regimentos, sobretudo o de Roque da Costa Barreto, serviram de modelo para todos os governadores da América portuguesa.

Em Goiás, por exemplo, o governador João Manoel de Mello (1759-1770) saiu de Portugal com uma Instrução, da qual constavam duas ordens específicas: prender os jesuítas que ainda viviam em

\footnotetext{
${ }^{2}$ Em 1640 a Dinastia de Bragança foi entronizada colocando, por conseguinte, fim à União Ibérica (1580-1640). Com o fim da união entre Portugal e Espanha, a coroa portuguesa foi administrada por essa dinastia. Antes, Portugal contou com outras dinastias reinantes, como a Dinastia de Borgonha ou Afonsina (1139-1385), Avis (1385-1580). Para o período moderno e o contexto da expansão ultramarina, o período da União Ibérica e da Dinastia de Bragança são essenciais na compreensão da política régia.
} 
Goiás e investigar as queixas e denúncias contra o governador Conde de São Miguel, D. Álvaro Xavier Botelho de Távora (1755-1759).

Vale destacar que a Instrução e o Regimento foram as maneiras utilizadas pela Coroa portuguesa para delegar poderes, "condicionadas pela realidade encontrada em cada uma" das conquistas ultramarinas (CONSENTINO, 2005). Não se tratava de poderes ilimitados, mas funções concedidas de acordo com a realidade de cada região. A delegação cobriu um período limitado - normalmente entre três e cinco anos para os governadores - e um campo de ação igualmente restrito. No caso da Capitania de Goiás, havia, ao longo do século XVIII, ao menos duas prioridades: o ouro e os indígenas. Em face disso, os governadores receberam ordens para contemplar nas suas ações, na maioria das vezes, tais questões.

O título de "governador e capitão-general" permitia, assim, ao ocupante do cargo, formar regimentos. Mais do que mera execução das ordens do rei português, os governadores usaram das patentes como instrumentos de mando. Os membros das Ordenanças e Milícias ${ }^{3}$ transformaram-se em grandes aliados dos governadores. Capitães, alferes, sargentos, furriéis, tenentes e tantos outros se imiscuíam com os governadores e desenvolveram, com o passar dos anos, uma relação de cumplicidade e troca de favores.

Governar compreendia a conquista de terras, a procura de riquezas naturais, a concessão de cargos aos indivíduos que se aventuram a executar as ordens do rei, pacificar o "gentio", formar vilas e arraiais. Mas não se limitava somente a essas tarefas. O governo também era de ordem espiritual. Rei e Igreja eram inconfundíveis na sociedade de Antigo Regime. Um andava do lado do outro e, portanto, governar também significava levar o cristianismo para esses lugares (MORAES, 2012). Busca-se, nas próximas linhas, analisar a historiografia sobre os governadores na Capitania de Goiás. Num primeiro momento situamos o debate sobre os governadores num espaço mais amplo, isto é, na historiografia brasileira, portuguesa e de brasilianistas. Essa incursão busca, sobretudo, compreender as obras de maior influência sobre os governadores. No segundo momento, são analisadas três obras sobre os governadores de Goiás.

\section{GOVERNADORES DIANTE DA HISTORIOGRAFIA}

Aqui não exploraremos todas as obras e pesquisas acerca dos governadores. Cumpre, então, ressaltar algumas linhas gerais da historiografia. Percebe-se que a historiografia utilizou-se dos governadores como (sub) tema e/ou como rito de passagem. Nos grandes compêndios de "História do Brasil”, os governadores apareceram como aqueles indivíduos que, despidos da ostentação que viviam

\footnotetext{
${ }^{3}$ A organização militar na América portuguesa era dividida em três linhas. Segundo Gomes (2013), a primeira linha era chamada de "Companhia de Dragões". Seus membros recebiam soldo e ficavam responsáveis pela defesa externa do território. A segunda linha, por seu turno, englobava os "Regimentos Auxiliares ou Milícias". Responsáveis pela defesa interna, os indivíduos desse regimento eram comandados por um capitão-mor. Por fim, a terceira linha recebia o nome de "Ordenanças" que, de fato, se constituía em maior número e incluía, por vezes, "pardos" e "negros".
} 
em Portugal nos seus palácios, foram empurrados para o ultramar. Eram a representação mais precisa e exata da figura do português em terras desconhecidas. Receberam ordens diretas do rei e, nas conquistas portuguesas, tinham a árdua tarefa de governar os povos.

Assim, quando se falou da Igreja Católica no ultramar, das leis régias, dos órgãos da administração colonial, do processo de dominação e extermínio dos gentios, da escravidão, os governadores foram evocados como subtema de um tema maior. Se o objetivo era falar da administração colonial, traziam para discussão a figura dos governadores. Por outro lado, os governadores foram estudados como rito de passagem. Mais especificamente, eram tidos como aquele conteúdo essencial, mas dispensável numa obra de história. Nessa perspectiva, a falta de estudo sobre os governadores ou a citação desse (sub)tema não comprometia, pois, o estudo sobre o Brasil Colonial. Bastava arrolar os nomes de alguns governadores ou a instituição do Governo-Geral e o modelo das capitanias hereditárias para dar conta desse (sub)tema.

Essa prática de "fazer história" sobre os governadores se estendeu. Segundo Fico e Polito (1992), nas décadas de 1970 e 1980 vários programas de pós-graduação criados no Brasil possibilitaram a proliferação de estudos sobre a época colonial. Trabalhos ensaísticos - como, por exemplo, o de Caio Padro Júnior e Sérgio Buarque de Holanda - viabilizaram o desenvolvimento de pesquisas empíricas que colocaram, por conseguinte, em questionamento algumas teses da historiografia de outrora.

Fernando Novais (1986), em Portugal e Brasil na crise do Antigo Sistema Colonial, obra publicada pela primeira vez em 1979, reproduziu alguns argumentos de Caio Padro Júnior - sobretudo a ideia de "colônia" e "metrópole". Ali se esboçou uma síntese das relações entre o Brasil e Portugal. O conceito de Antigo Sistema Colonial foi, de fato, uma das contribuições mais significativas de Novais (1986). Havia uma tentativa de compreender o Brasil num contexto maior: do mercantilismo europeu, da circulação de mercadorias, de capitalismo comercial e da influência das "colônias", sobretudo da América portuguesa, no desenvolvimento do capitalismo.

Por outro lado, trabalhos como os de Ciro Flamarion Cardoso (1980), Jacob Gorender (2011) e Manolo Florentino (1997) chamaram atenção, nas suas pesquisas, para a lógica interna das relações sociais vividas na América portuguesa. Relativizou-se a presença do "capital europeu" na América portuguesa para dar relevância às dinâmicas próprias do espaço da conquista. Foi embebido dessa perspectiva que, ainda em meados de 1980, Manolo Florentino demonstrou com sua tese, publicada em 1997, que o tráfico de escravos não foi controlado pelos tentáculos da Coroa Portuguesa. Em costas negras, Florentino (1997) destaca que, na realidade, o controle advinha de outro lugar: da própria América. Eram os negociantes moradores da Praça do Rio de Janeiro que controlavam esse negócio. O autor derrubava, assim, a tese de que o Brasil era um apêndice de Portugal e de que as relações mantidas aqui acompanharam, de maneira absoluta, as diretrizes portuguesas.

A contribuição dos trabalhos supracitados foi, a nosso ver, desvendar e analisar os mercados internos existentes na América portuguesa. Com isso, colocaram em xeque a ideia de "dependência" ou 
“exclusivismo colonial”, defendido por Fernando Novais (1986) na sua abordagem de Antigo Sistema Colonial.

Nesse período os governadores eram ainda estudados como subtema e/ou rito de passagem. A historiografia pareceu ter se interessado por outros temas que, naquela altura, pareciam mais importantes para explicar as relações vividas na América portuguesa e no contexto do Império português. A exceção se encontrava na obra dos brasilianistas, autores estrangeiros, especialmente norte-americanos, que se interessaram pelo estudo do Brasil. Isenta de visões nacionalistas e/ou de preconceitos acerca do passado colonial, a historiografia brasilianista começou a colocar no debate sobre a América portuguesa a importância de duas coisas: as instituições locais e dos grupos locais.

Nesse interim, os governadores foram projetados como entrepostos entre a Coroa portuguesa e os grupos locais, como elos que ligavam Portugal e o ultramar. A discussão dessas relações mostrou que muitas instituições no ultramar não seguirem fielmente os modelos dos órgãos metropolitanos e foram amalgamadas com os valores e práticas locais. Não se tratava do puro localismo ou de uma História Regional, mas de valorização do intercâmbio entre “interesses locais e reinóis”.

A nosso ver, aqui se esboçaram alguns elementos importantes para os estudos dos governadores. Ao reconhecer que os grupos locais foram essenciais para assegurar o mando nas conquistas, a historiografia trouxe, por conseguinte, uma nova dimensão para o debate sobre a administração colonial. Iniciou-se, ainda timidamente, o deslocamento dos olhos do Estado português para a realidade ultramarina. Ora, se Raimundo Faoro, em Os Donos do poder, argumentou que o "Estado português precedeu a formação da sociedade colonial"' (FAORO, 1975), o interesse dessa nova historiografia recaiu em verificar que no ultramar muitas instituições portuguesas se diferenciaram radicalmente das suas congêneres. Em linhas gerais, ficou demonstrado que, durante o processo de conquista, ocorreram fissuras e muitas leis régias não foram aplicadas nos espaços ultramarinas. Além disso, a historiografia desvendou a presença de grupos sociais, práticas e valores distintos de Portugal. Era uma sociedade diferente. Diferente não significa que era peculiar ou totalmente discrepante de Portugal. Atentou-se para o fato que as sociedades de conquistas - como a América portuguesa - incorporaram, sim, valores e práticas de Portugal, mas que, nesse processo, outros grupos influenciaram: africanos, indígenas, franceses ou holandeses.

Nesse sentido, Luís Felipe de Alencastro (2000), no trabalho O trato dos viventes, chamou a atenção para a importância de estudar o Brasil como uma área interligada pelo contato com o Atlântico Sul. A América portuguesa não foi peculiar no modelo de colonização, pois apresentou características comuns com outras áreas de conquistas. Assim, o ineditismo da historiografia brasilianista não estava em substituir a centralidade de Portugal pela importância do local, mas em se preocupar mais com o que foi modificado, adaptado e em comparar o que era divergente e/ou convergente. Um dos brasilianistas responsáveis por introduzir essa nova percepção da América portuguesa e da própria noção de Império português foi, certamente, Charles Boxer (1973; 2002). De um lado, Salvador de Sá e a luta pelo Brasil e Angola e, de outro, O império marítimo português resultaram em uma nova interpretação. Tanto a primeira 
obra como a segunda deslindaram algo importante: o estudo de indivíduos e instituições presentes no ultramar. Com efeito, o ponto de partida foi a análise das condições pelas quais governadores, câmaras e as casas de misericórdias se instalaram no ultramar. Boxer mostrou que essas instituições faziam parte do Império português e que, inicialmente, foram concebidas em Portugal. Mais do que isso, as câmaras e as casas de misericórdias "garantiam uma continuidade que os governadores, os bispos e os magistrados transitórios não podiam assegurar" (BOXER, 2002, p. 286).

A contribuição realmente decisiva foi constatar que os governadores e das instituições presentes no ultramar funcionaram como lugar de fusão dos interesses régios e de grupos locais. Não era a mera separação do que existia no Brasil ou em Portugal. O "fazer história" desses autores e autoras cotejaram uma "agenda comum" - regimentos, leis, valores oriundos de Portugal -, mas, ao mesmo tempo, as vicissitudes pelas quais os vassalos no ultramar passavam ao adentrar o território das capitanias, vilas e arraiais. Quer dizer, estes personagens também perseguiam seus próprios interesses, que, muitas vezes, não se coadunavam com as diretrizes de Lisboa. Os inúmeros processos de devassa acusando governadores - o caso de alguns governadores da Capitania de Goiás, como o Conde de São Miguel, Tristão da Cunha Meneses e D. João Manuel de Meneses - foi, de longe, indícios desse tipo de prática.

Uma das obras mais recentes - e que causou grande repercussão na historiografia brasileira foi à coletânea organizada por João Fragoso, Maria Fernanda Bicalho e Maria de Fátima Gouvêa (2001), O Antigo Regime nos trópicos: a dinâmica imperial portuguesa (séculos XVI-XVIII).4 De fato, houve ali a tentativa de propor uma nova leitura sobre o Império português e, sobretudo, da América portuguesa. Os autores propõem-se "a compreender a sociedade colonial e escravista na América enquanto uma sociedade marcada por regras econômicas, políticas e simbólicas de Antigo Regime” (FRAGOSO; GOUVÊA; BICALHO, 2001, p. 21). Há, em toda a obra, uma tentativa de repudiar - mas sem negar a importância - o conceito de Antigo Sistema Colonial como modelo explicativo da América portuguesa. Para esses autores, tal conceito implicou na separação entre o que acontecia em Portugal e na América portuguesa. Dizer que a América portuguesa era, socialmente, constituída por traços de Antigo Regime era uma forma de afirmar as semelhanças desses dois mundos.

Em geral, os valores e práticas de Antigo Regime correspondiam a uma sociedade marcada pela hierarquia ou, mais especificamente, pela "ordem natural das coisas". Os homens do Antigo Regime concebiam o mundo organizado por Deus e, portanto, corroboravam com a ideia de que cada pessoa ocupava socialmente um lugar determinado. Tratava-se, desse modo, de uma sociedade estamental, assentada no privilégio e no governo monárquico, além de ser marcada pelo entrelaçamento entre política e religião. Entretanto, na América portuguesa e nas áreas de conquistas, o Antigo Regime assumiu , vale destacar, "feições peculiares, como a escravidão, e existência da autointitulada nobreza da terra, a mobilidade social mais ampla e, sobretudo, os usos e costumes locais, inclusive no âmbito legal" (FRAGOSO; GUEDES; KRAUSE; 2013, p. 167).

\footnotetext{
${ }^{4}$ A repercussão pode ser vista na produção de uma importante historiadora brasileira, Laura de Mello e Souza, nomeadamente em sua obra O Sol e a Sombra: política e administração na América Portuguesa do século XVIII (SOUZA, 2006).
} 


\section{A HISTORIOGRAFIA DE GOIÁS: DEVASSAS, GOVERNADORES E ADMINISTRAÇÃO COLONIAL}

Cumpre agora analisar as obras produzidas sobre os governadores da Capitania de Goiás. O primeiro trabalho a ser destacado é o de Luís Palacín, publicado em 1977. Tratava-se de um pequeno artigo com o título Limites e possibilidades de um administrador colonial: o governo do Conde dos Arcos em Goiás (1749-1755). Ali o historiador jesuíta ${ }^{5}$ procurou desenvolver o conceito de "limites da consciência possível”. Tal ideia foi retirada de Lucien Goldman (1972), da obra A criação cultural na sociedade moderna. O próprio Palacín assinala no seu artigo a influência desse autor.

Segundo Palacín (1977), a atividade governativa do Conde dos Arcos pode ser pensada com base no conceito de "limites da consciência possível", o qual remete para as "injustiças" que o governador reconhecia como realidade do mundo colonial, sobre a qual, no entanto, não haveria meios de interferir. Assim, na leitura das fontes, Palacín (1977, p.122) percebeu que o Conde dos Arcos nutria profunda “compaixão" pelos escravos e indígenas. O governador tentou proteger esses grupos, mas, no final, se viu limitado pelas estruturas sociais e políticas da Coroa portuguesa. Assim, "o traço mais belo do caráter do Conde é, sem dúvida, seu amor à justiça, levados até a defesa dos direitos dos humildes contra as arbitrariedades dos poderosos."

Haveria, portanto, um jogo entre "limites e possibilidades" para um governador colonial. Conde dos Arcos experimentou isso na sua administração da Capitania de Goiás quando buscou proteger os escravos e indígenas. Seu governo foi marcado, entre outras coisas, pela "defesa constante dos direitos dos sem direitos, escravos e os índios. Empresa perigosa e que haveria de concitar-lhe muitas inimizades" (PALACÍN, 1977, p. 123). Ao mesmo tempo em que Palacín insiste no "caráter piedoso e misericordioso" do governador, não arrola, por seu turno, documentos ou palavras do governador para comprovar seus argumentos.

Por outro lado, talvez o conceito de "limites da consciência possível" aponte para uma característica marcante do ofício de governador, na compreensão de Palacín: apesar da nobreza e dos títulos dos governadores, o campo de autonomia desses indivíduos era tolhido ou simplesmente estrangulado pelas mãos fortes da Coroa portuguesa. Nesse sentido, o autor acrescenta que, no plano econômico, os governadores não podiam conceder "subvenções, eximir de impostos, criar cargos ou funções de assessoria, etc. Poderiam, isso sim, recomendar estas ou outras medidas para o governo central" (PALACÍN, 1977, p. 127).

Seguindo a linha de raciocínio de Palacín, o governador era apenas uma peça do tabuleiro do "governo central". Não havia muitos espaços jurisdicionais ou políticos para agir no ultramar. Comparando com outras obras historiográficas, essa interpretação de Palacín se aproxima,

\footnotetext{
5 "Historiador jesuíta" foi um termo criado por Rogério Chaves da Silva (2006; 2015) como forma de classificar a produção historiográfica de Luís Palacín.
} 
indiretamente, de Raimundo Faoro, em Os donos do poder, cuja tese acerca da expansão ultramarina e o Brasil Colonial reside na afirmação de que a coroa portuguesa transplantou leis e valores para as instituições. Assim, a formação do Estado português precedeu, na interpretação de Faoro (1975), a constituição da sociedade na América portuguesa.

Nesse sentido, os governadores foram - do início ao fim - os representantes do Estado português. Por isso não tinham autonomia e careciam, portanto, de iniciativa própria. Intencionalmente, a Coroa portuguesa concedeu um campo limitado de jurisdição para os governadores. Em face disso, Palacín considera que Conde dos Arcos fez um "bom governo", pois assegurou, durante o seu governo, a justiça, a paz social, a arrecadação dos impostos e, sobretudo, o sucesso da instalação da Capitania de Goiás após seu desmembramento de São Paulo, em 1749.

Em resumo, a tese resultante desse primeiro trabalho sobre governadores é que "Governar no século XVIII, e com maior razão uma capitania colonial, era uma função que carecia da complexidade e da riqueza de possibilidades que tem na atualidade" (PALACIN, 1977, p. 127). Pela concepção de Palacín, haveria, ao final, mais "limites" do que "possibilidades" para a administração de um governador. O Estado estendeu seus sustentáculos aos domínios portugueses de tal maneira que, mesmo distante do "governo central", esses governadores não puderam mudar ou aplicar suas ideias nesses espaços.

Ora, se essa era a perspectiva de Palacín em 1977, no entanto, em 1983, no livro Subversão e corrupção, o autor se deparou com o processo de devassa instaurado contra o governador Conde São Miguel e seus ministros. O documento mostrou a Palacin (1983) que, sim, os governadores tinham mais "possibilidades" que "limitações". Os crimes imputados ao Conde de São Miguel e seus ministros atestavam que, diferentemente do que aconteceu no governo do Conde dos Arcos, os governadores na América portuguesa não pautaram seu viver na obediência irrestrita ao rei. Pelo contrário, imiscuíramse pelos negócios da capitania e tiraram proveito das jurisdições que lhe eram imputadas.

Subversão e corrupção é, a nosso ver, um dos trabalhos mais meticulosos do historiador Palacín no que se refere ao manejo de fontes. Quer dizer, a transcrição e a leitura da devassa do desembargador Brandão mostraram que, em contraposição a trabalhos anteriores, Palacín (1983) concedeu uma atenção especial ao cotejamento das ações e visões dos indivíduos envolvidos no processo.

Não se tratou apenas de evidenciar como "verdadeiro ou falso" certas alegações. O refinamento do estudo de Palacín (1983) reside, precisamente, em "dar voz" às testemunhas arroladas no processo da devassa, mas também de acrescentar, quando possível, outras visões. Foi esse cruzamento de visões díspares que permitiu ao historiador remontar, em sua obra, o complexo e intrigado contexto da capitania e das relações encetadas pelo Conde de São Miguel. Evidentemente, muitos termos e conceitos não foram esclarecidos devidamente - como as ideias de subversão e corrupção. Mesmo assim, a contribuição da obra para a historiografia de Goiás se deve, sobretudo, aos documentos ali citados.

Palacín analisa a devassa elaborada pelo desembargador Brandão. Iniciada em 1763, a devassa só foi finalizada, efetivamente, em 1765. A acusação recaia sobre um número significativo de funcionários régios, a exemplo do governador Conde de São Miguel, os ouvidores Agostinho Luís 
Ribeiro Vieira, Antônio da Cunha Soto Maior e Francisco Atouguia Bittencourt, o provedor da Fazenda Real, Luiz Antônio Rozado da Cunha, os tesoureiros Guilherme José Pereira, Fernando José Lela, entre outros. Pelo inquirir das testemunhas e o rastreamento das receitas e despesas da Fazenda Real, Brandão descortinou, na visão de Palacín (1983), o universo de "roubos e descaminhos" na Capitania de Goiás.

O desembargador finalizou a devassa descobrindo que, na realidade, das vinte e quatro acusações contra o governador Conde de São Miguel, apenas uma era imputável. Tratava-se do comércio de escravos praticado pelo dito governador. As outras acusações incidiam sobre a Casa de Fundição e funcionários da Fazenda Real. Nomes como João Álvares Vieira, Bonifácio Xavier de Aguirre e o tesoureiro Antônio José de Barro Leitos apareceram no rol dos culpados.

Palacín (1983, p. 95) chega ao final de seu estudo sobre os governadores e ministros da capitania afirmando: "A corrupção, no aspecto econômico, parece ter sido um fato generalizado com respeito ao funcionalismo, mas sempre contida nos limites estreitos - mesquinhos? sujos? - do passado". A despeito desse tipo de declaração, o estudo de Palacín se diferenciou dos demais pelo fato de traçar, nomear, analisar e refletir sobre a prática governativa.

Os nomes descortinados pelo historiador ao ler a devassa de Brandão apontam, com efeito, para um dos procedimentos mais refinados realizados por esse historiador naquela altura. Ao contrário de generalizações trazidas em estudos anteriores - como aqueles acerca do Conde dos Arcos -, o texto Subversão e corrupşão se preocupa com os pormenores e as lógicas internas contidas nas ações dos governadores e ministros. Embora muitos dos conceitos ali aplicados carregassem certo grau de anacronismo ou não recebessem a devida fundamentação, o estudo de Palacín se traduz, no quadro historiográfico, como uma obra pioneira no estudo da governança.

Os caminhos trilhados por Palacín e as pistas lançadas nos seus estudos foram seguidos por outro trabalho historiográfico: a dissertação de mestrado de Simone Cristina Schmaltz de Rezende e Silva (2002), Criação e consolidação da Capitania de Goiás no universo colonial: o governo do Conde dos Arcos, 1748 1755. A autora realizou o estudo dos governadores como pretexto para conhecer e analisar a administração colonial e se utilizou da figura do Conde dos Arcos, primeiro governador na Capitania de Goiás após o desmembramento de São Paulo, em 1749, para abordar a estrutura administrativa portuguesa no ultramar.

O texto de Rezende e Silva (2002) está dividido em três capítulos. O primeiro é um apanhado geral da legislação portuguesa do século XVIII, da estrutura administrativa ultramarina e da geografia do território lusitano. O segundo capítulo foi escrito na tentativa de compreender o "Brasil inserido no Império português". O terceiro capítulo e último abordou especificamente a criação da Capitania de Goiás e o governo do Conde dos Arcos. De antemão, se percebe que a autora buscou, excessivamente, contextualizar o Brasil e a Capitania de Goiás nos quadros do Império português. Nas palavras da autora, "O presente trabalho visa elucidar como as estruturas de poder político-administrativas lusas foram absorvidas pelo território colonial e, particularmente, pela Capitania de Goiás" (REZENDE E SILVA, 2002). Palavras como "inserção", "absorvidas", "estrutura administrativa”, "controle metropolitano” são 
abundantes no texto. Desse modo, as linhas destinadas à explicação do aparato administrativo e burocrático da Coroa portuguesa atravessaram boa parte da argumentação da autora.

A abordagem reflete outra característica da historiografia acerca dos governadores: a busca por aquilo que era comum, igual ou reproduzido nos domínios ultramarinos. Como pano de fundo, esse tipo de abordagem parte do princípio de que os governadores, como representantes da Coroa portuguesa, implantaram as mesmas estruturas observadas em Portugal. As funções do governador eram fiscalizar e informar ao rei a situação das capitanias e, sobretudo, organizar o espaço ultramarino para que as ordens e leis régias fossem aplicadas. Em certo sentido, parece ter um "destino manifesto" nesse tipo de historiografia: a negativa de um espaço de manobra para os governadores e, tampouco, para as instituições locais da América portuguesa. Talvez tenha sido este um dos aspectos estruturantes da historiografia sobre os governadores, da qual Rezende e Silva (2002) se aproximam muito. Em seu texto, o governador Conde dos Arcos aparece como o fiel executante das ordens metropolitanas.

De maneira geral, a autora admite que um dos objetivos do trabalho foi "propor uma nova leitura na história de Goiás no período setecentistas, sob uma perspectiva político-administrativa" e que permitisse, ao final de tudo, apresentar " a arquitetura de poderes da qual a América portuguesa era integrante" (REZENDE E SILVA, 2002, p. 11). Vale destacar, nesse sentido, que a "arquitetura de poderes" referenciada pela autora compreendia, mais especificamente, os órgãos da administração portuguesa no ultramar e, não raro, os poderes dos governadores. Nesse caso, o Conde dos Arcos foi escolhido como objeto de estudo para mostrar como se deu o início e a estruturação de uma capitania de "minas". Em outras palavras, Conde dos Arcos foi o primeiro governador de Goiás. Para a autora, se tornou necessário investigar o contexto vivido pelo referido governador em Goiás em um dos momentos mais importantes da capitania, ou seja, sua criação e instalação. Por conseguinte, a "arquitetura de poderes" encabeçada pelo Conde dos Arcos se resumiu, segundo Rezende e Silva (2002), na estruturação dos órgãos administrativos, na organização da situação militar, na catequização das nações indígenas e, por fim, o governador ficou responsável por abolir da cobrança a capitação e retornar ao sistema do quinto. ${ }^{6}$

O conceito de "arquitetura de poderes" citado pela autora parece ter se perdido ao confrontar e valorizar em demasia as estruturas administrativas lusas. Pouco se discutiu sobre a atuação do governador na capitania ou sobre a visão do Conde dos Arcos acerca de suas ações e práticas governativas. Com efeito, muitas das citações de documentos coevos traziam despachos do Conselho Ultramarino, regimentos e instruções. Dificilmente esses documentos faziam alusão aos outros "poderes" existentes na capitania e que, de igual forma, faziam parte dessa vasta "arquitetura de poderes", como, exemplo, a câmara, a Fazenda Real, as milícias e as ordenanças.

A relevância foi dada àquilo que era "oficial", "formal", "estrutural” e, desse modo, houve a supressão daquilo que, na prática, foi considerado importante por aqueles sujeitos do século XVIII. A

\footnotetext{
${ }^{6}$ Quinto ou quintamento era o imposto cobrado e recolhido pela Coroa portuguesa nas áreas de mineração. O ouro em pó era fundido e retirava-se $20 \%$ para a Coroa portuguesa.
} 
aparente "racionalidade" e "formalização" da administração portuguesa levou a autora - assim como Palacín, nos seus estudos - a supervalorizar regimentos e órgãos, em detrimento das vivências dos governadores e ministros.

Se Rezende e Silva (2002) deu atenção especial às estruturas administrativas, por sua vez, outro trabalho na historiografia procurou coadunar tais estruturas com a experiência dos governadores no ultramar. Tratava-se da investigação desenvolvida por João Paulo da Silva Aparício, que resultou na dissertação de mestrado, defendida em 1998. Intitulado Governar no Brasil Colonial: a administração de Luís da Cunha Meneses nas Capitanias de Goiás (1778-1783) e de Minas Gerais (1783-1788), e publicado posteriormente, o trabalho buscou analisar a trajetória administrativa do governador pertencente à família dos Cunha Meneses nas duas capitanias. O estudo foi dividido em dois momentos: o primeiro aborda o "Cenário e o homem" e o segundo tem por tema “Atuação: governar na colônia”. Na primeira parte, Aparício (2015) concentrou a narrativa na análise do perfil social de Luís da Cunha Meneses. Mostrou a origem social desse governador, os títulos da sua família, os serviços prestados no contexto da Dinastia de Bragança e o recebimento do hábito da Ordem de Cristo. No segundo momento, o estudo versou sobre as capitanias de Goiás e Minas Gerais. Nessa parte do estudo, a "elite local” ganhou evidência. Desse modo, Aparício sublinhou a atuação do governador ao mesmo tempo em que se preocupou em desvendar as relações com os "poderes locais".

De imediato, o que sobressai na pesquisa de Aparício (2015) é a extensa documentação consultada pelo historiador. Talvez por morar em Portugal e ter maior acesso à documentação ultramarina, Aparício cotejou uma variedade de fontes. Desde plantas cartográficas dos aldeamentos até rendimentos e despesas das capitanias governadas por Luís da Cunha Meneses foram analisadas em seu trabalho. Sem dúvida, foi o cruzamento dessa variedade de fontes que conferiu fôlego à pesquisa e possibilitou o detalhamento da trajetória do governador. Não por acaso, a figura do governador foi perspectivada no que se refere à sua atuação com a fazenda, a justiça, a administração ultramarina propriamente dita, a organização militar, a catequização e o aldeamentos dos "gentios".

A figura de Luís da Cunha Meneses foi problematizada em um documento do século XVIII, as Cartas Chilenas - uma sátira escrita pelo ouvidor de Vila Rica, Tomás António Gonzaga, que desenhou uma imagem demasiadamente tirânica e autoritária da administração do governador. A historiografia e a literatura se apropriam desse documento para mostrar que, de fato, Luís da Cunha Meneses agiu arbitrariamente por onde andou. Contrariando esse tipo de abordagem, Aparício buscou desmontar essa imagem. Através “do diálogo comparativo entre os testemunhos coevos e a obra do ouvidor de Vila Rica, avaliou-se a dimensão e a veracidade do retrato.” (APARÍCIO, 2015, p. 27)

Nos apontamentos de Palacín (1977, 1983), assim como nos de Rezende e Silva (2002), prevalece a ideia de prevalência da "administração central" sob a "administração local". Ambos historiadores sustentaram o argumento de que, nos espaços ultramarinos, os governadores não possuíam horizonte de autonomia. Cabia a eles, sobretudo, executar tenazmente as ordens do rei, mesmo que isso significasse agir tiranicamente, perseguir e colocar na cadeia ministros, ouvidores e funcionários régios. Aparício 
(2015) parece não ter seguido à risca esse tipo de concepção. Embora o autor afirme que, sim, a "administração central", especialmente com o Marquês de Pombal, tenha engrossado seu mando no ultramar, há o reconhecimento de que o jogo das relações era baseado no jogo de dicotomias, nas relações entre o centro e o local, de interdependência entre uma instância e outra.

O pretexto de estudar o governador Luís da Cunha Meneses nas duas capitanias e discutir a imagem do Fanfarrão Minésio trouxe, portanto, para o debate sobre a administração colonial, alguns pontos importantes. O exaustivo trabalho com as fontes, o cruzamento de documentos diferentes, o uso de bibliografia especializada, a tentativa de síntese e as considerações sobre a governança no ultramar foram estruturais para a compreensão de Aparício (2015) sobre a prática governativa.

O esboço biográfico e social traçado pelo autor foi decisivo na compreensão da figura de Luís da Cunha Meneses. O rastreamento da trajetória desse governador em Portugal, como os títulos, as mercês e os serviços prestados, permitiram, com efeito, dimensionar os valores e práticas com os quais Luís da Cunha Meneses norteou suas ações. Não bastou apenas arrolar os inúmeros feitos desse governador no ultramar ou se basear na imagem construída pelas Cartas Chilenas. Tais aspectos poderiam ajudar como ponto de partida, mas não como ponto de chegada.

Aqui, portanto, reside um dos pontos importantes desse trabalho: o uso da trajetória como ferramenta analítica. No mesmo sentido, outro elemento foi fundamental: a constatação que havia, de fato, fissuras e "dicotomias" na administração colonial. Pela linha interpretativa de Aparício (2015), a distância entre Portugal e suas colônias, a indistinção das jurisdições de governadores e demais ministros e as crises que assolaram a Coroa portuguesa no final do século XVIII fizeram com que, em maior ou menor grau, a "administração central” cedesse às pressões locais.

\section{CONSIDERAÇÕES FINAIS}

De maneira geral, observou-se que a historiografia produzida sobre a Capitania de Goiás tratou do tema dos governadores a partir de três vertentes: primeiro, a partir das devassas e de acusações; em segundo, em uma perspectiva preocupada em traçar o perfil dos governadores da Capitania de Goiás; e, por último, como tentativa de compreender os meandros da administração colonial com base nas ações dos governadores. Devassas, governadores e administração colonial são, assim, temas com os quais a historiografia lidou com a figura dos governadores.

Como se viu, há três trabalhos preocupados com essas temáticas. Os trabalhos de Luís Palacin, nomeadamente Subversão e corrupscão e o artigo Limites e possibilidades de um administrador colonial, textos que trabalham a figura dos governadores por meio de devassas e acusações. No mesmo sentido, Palacín buscou dimensionar os aspectos da "administração pombalina" em Goiás. Há, também, o trabalho de Aparício, Governar no Brasil Colonial, no qual o autor busca traçar a trajetória administrativa de Luís da Cunha Meneses na Capitania de Goiás e Minas Gerais. Tal estudo é, nesse sentido, uma tentativa de estudar a figura de um único governador. 
Outro trabalho aqui abordado também buscou rastrear a trajetória de um governador, o Conde dos Arcos, na Capitania de Goiás. Trata-se do trabalho de Simone Cristina Schmaltz de Rezende e Silva, Criação e consolidação da Capitania de Goiás no universo colonial. A diferença é que, além de incorporar uma reflexão sobre a prática governativa do Conde dos Arcos, a autora também realiza uma discussão sobre a administração colonial.

Assim, pode-se dizer que foram esses trabalhos que investigaram os governadores na Capitania de Goiás. É certo que, na maioria dos trabalhos e estudos, os governadores abundam em citações. Entretanto, cita-se, mas não se aprofunda. Quer dizer, ganham destaque aqui ou ali, mas dificilmente são examinados com maior precisão ou tidos como objeto de estudo. Além disso, no âmago da historiografia, houve uma tentativa de olhar para esses governadores ou para os/as historiadores/as que lidam com esse tipo de objeto e denominá-los/las como temas e autores "positivistas, rankeanos". Fazer uma história sobre os governadores é, antes, fazer uma história linear e factual. Esse tipo de posicionamento só foi tardiamente problematizado quando, em meados de 2001, a coletânea $O$ Antigo Regime nos trópicos (FRAGOSO; BICALHO; GOUVEIA, 2011) inseriu uma nova perspectiva para o estudo desses indivíduos, não mais como "déspotas esclarecidos" ou "representantes do absolutismo", mas como indivíduos que perseguiam seus próprios interesses, traçavam estratégias, firmavam alianças com os poderes locais.

Os trabalhos produzidos sobre os governadores da Capitania de Goiás traçaram caminhos e escrutinaram a atuação desses indivíduos numa capitania ultramarina. Não há dúvidas que forneceram uma visão importante sobre o processo de conquista do Império português na América portuguesa. Resta, portanto, compreender o vínculo dos governadores com os “potentados locais". Ou seja, como os governadores relacionavam-se com os moradores locais para estabelecer seu mando e poder.

\section{REFERÊNCIAS}

APARÍCIO, J. P. da S. Governar no Brasil Colonial: a administração de Luís da Cunha de Meneses nas capitanias de Goiás (1778-1783) e de Minas Gerais (1783-1788). São Paulo: Hucitec, 2015.

ALENCASTRO, L. F. de. O Trato dos Viventes: formação do Brasil no Atlântico Sul. São Paulo: Companhia das Letras, 2000.

BOXER, C. R. O império marítimo português, 1415-1825. São Paulo: Companhia das Letras, 2002.

BOXER, C. R. Salvador de Sá e a luta pelo Brasil e Angola, 1602-1686. São Paulo: Companhia Editora Nacional, 1973.

CARDOSO, C. F. As concepções do "sistema econômico mundial" e do "antigo sistema colonial": a preocupação obsessiva com a "extração de excedente". In: LAPA, J. R. do A. (org.). Modos de produção e realidade brasileira. Petrópolis: Vozes, 1980. p. 109-132. 
CONSENTINO, F. C. C. Governadores Gerais do Estado do Brasil (séculos XVI e XVII): ofício, regimentos, governação e trajetórias. Tese (Doutorado em História) - Universidade Federal Fluminense, Niterói, 2005.

DIAS, T. C. O lingua e as línguas: aldeamentos e mestiçagens entre manejos de mundo indígenas em Goiás (1721-1832). Tese (Doutorado em História) - Universidade Federal de Goiás, Goiânia, 2017.

FAORO, R. Os donos do poder: formação do patronato político brasileiro. Porto Alegre: Globo; São Paulo: Edusp, 1975.

FICO, C.; POLITO, R. A História no Brasil (1980-1989): elementos para uma avaliação historiográfica. Ouro Preto: Ed. da UFOP, 1992.

FLORENTINO, M. Em costas negras: uma história do tráfico de escravos entre África e o Rio de Janeiro (séculos XVIII e XIX). São Paulo: Companhia das Letras, 1997.

FRAGOSO, J.; BICALHO, M. F. B.; GOUVÊA, M. de F. S. (org.) O Antigo Regime nos trópicos: a dinâmica imperial portuguesa (séculos XVI-XVIII). Rio de Janeiro: Civilização Brasileira, 2001.

FRAGOSO, J; GUEDES, R.; KRAUSE, T. A América portuguesa e os sistemas atlanticos na Época Moderna. Monarquia pluricontinental e Antigo Regime. Rio de Janeiro: Ed. da FGV, 2013.

GOLDMANN, L. A Criação Cultural na Sociedade Moderna: Por uma sociologia da totalidade. São Paulo: DIFEL, 1972.

GORENDER, J. O escravismo colonial. São Paulo: Perseu Abramo, 2011.

GOMES, D. V. Dos corpos militares no território do ouro: a composição da força militar nas minas e capitania de Goiás (1736-1770). Dissertação (Mestrado em História) - Universidade Federal de Goiás, Goiânia, 2013.

MORAES, C. de C. P. Do corpo místico de Cristo: irmandades e confrarias na capitania de Goiás (17361808). Goiânia: Ed. da UFG, 2012.

MONTEIRO, N. G.; CUNHA, M. S. da. Governadores e capitães-mores do império atlântico português nos séculos XVII e XVIII. In: MONTEIRO, N. G.; CARDIM, P.; CUNHA, M. S. da (org.). Optima Pars: elites ibero-americanas do Antigo Regime. Lisboa: ICS, 2005, p. 250-251.

MONTEIRO, N. G. O crepúsculo dos grandes. A casa e o patrimônio da aristocracia em Portugal (17501832). Lisboa: Imprensa Nacional, 2003.

NOVAIS, F. A. Portugal e Brasil na Crise do Antigo Sistema Colonial (1777-1808). São Paulo: Hucitec, 1986.

PALACÍN, L. Limites e possibilidades de um administrador colonial: o governo de Conde dos Arcos em Goiás (1749-1755). Estudos Goianienses, n. 5, 1977.

PALACÍN, L. Subversão e corrup̣ção: um estudo da administração pombalina em Goiás. Goiânia: Ed. da UFG, 1983.

REZENDE E SILVA, S. C. S. de R. e. Criagão e consolidação da Capitania de Goiás no universo colonial: o governo do Conde dos Arcos, 1748-1755). Dissertação (Mestrado em História Social e das Ideias) Universidade de Brasília, Brasília, 2002.

SANTOS, F. V. dos. O governo das conquistas do norte: trajetórias administrativas no Estado do Grão-Pará e Maranhão (1751-1780). São Paulo: Annablume, 2011. 
SILVA, R. C. da. O jesuita e o historiador: a produção historiográfica de Luís Palacín sob o prisma da Matriz Disciplinar de Jörn Rüsen. Dissertação (Mestrado em História) - Faculdade de Ciências Humanas e Filosofia, Universidade Federal de Goiás, Goiânia, 2006.

SILVA, R. C. da. Reflexões sobre o "fazer histórico": uma história da historiografia em (sobre) Goiás (da década de 1920 à de 1990). Tese (Doutorado em História) - Universidade Federal de Goiás, Goiânia, 2015.

SOUZA, L. de M, e. O Sol e a Sombra: política e administração na América Portuguesa do século XVIII. São Paulo: Companhia das Letras, 2006. 